NATALIDAD: EL NÚMERO SÍ IMPORTA

Sergio Micco Aguayo 
SERGIO MICCO AGUAYO

Abogado. Master en Ciencia Política. Doctor en Filosofía Política. Profesor asociado del Instituto de Asuntos Públicos de la Universidad de Chile. Trabaja la historia de las ideas políticas y el papel del Estado y de lo público en el desarrollo contemporáneo. 


\section{NATALIDAD: EL NÚMERO SÍ IMPORTA}

\section{PRESENTACIÓN}

El año 2004 la tasa chilena de fecundidad fue de 1,9 hijos por mujer. Estamos bajo el recambio poblacional, lo que implica que los hijos nacidos por cada mujer no alcanzarán para renovar la población al momento de fallecer sus padres (Donoso, 2). Entre los censos de 1992 y 2002 una ciudad completa como Concepción dejó de nacer. ¿Cómo interpretar estos datos?

\section{INTRODUCCIÓN: LA NATALIDAD COMO PREGUNTA}

¿Es bueno que nazcan menos niños y niñas en Chile? ¿Qué dice de nosotros que los hijos e hijas de madres populares, muchas veces adolescentes y solteras, se agolpen en los colegios municipales y que, por el contrario, los descendientes de las familias de clases medias y altas retrocedan y disminuyan? ¿Por qué nuestro Producto Interno Bruto no deja de aumentar, pero nuestros bebés de disminuir? ¿Debe molestarnos que nuestras autopistas se llenen y nuestras plazas se vacíen y asfalten? ¿Somos un pueblo que teniendo menos niños es más responsable ecológicamente al desactivar la explosión demográfica global? ¿O pertenecemos a una comunidad que pierde vitalidad y no es capaz de expandirse, enriqueciendo la diversidad cultural mundial? ¿Cómo interpretar que nuestros colegios, aulas y cursos deban disminuir y nuestros hospitales, asilos y clubes del adulto mayor aumentar? ¿Es mejor o peor que tengamos menos jóvenes y más adultos mayores? ¿Nos haremos más conservadores y menos innovadores? ¿O, por el contrario, seremos más sabios y menos impetuosos? La inmigración producida por la futura escasez de mano de obra, ¿es positiva o negativa? ¿Nos debemos alegrar o atemorizar cuando argentinos, bolivianos y peruanos aumentan en población ante un Chile estancado? ¿No es esta ocasión para cooperar más, abrir mejor nuestras fronteras y expulsar nuestros temores? Preguntas.

Para algunos este ejercicio es una soberana pérdida de tiempo. Simplemente debemos constatar que vivimos una transición demográfica, como tantos otros pueblos más desarrollados; transición cuyo enjuiciamiento es tan útil como evaluar si es bueno o malo que amanezca. Los más afirman que lo sabio es dejar tan complicadas cuestiones en manos de la libertad de las personas, de la estrategia de las empresas y de la autonomía de las comunidades. En el presente ensayo sostendremos, por el contrario, que: a) el envejecimiento y reducción de la población nacional son cuestiones políticas negativas; b) es gracias a la natalidad que hay vida, libertad, acción, pluralidad y progreso en la historia; c) un resurgir de la natalidad será con los derechos de la mujer y el respeto de la naturaleza, o no será; y d) las sociedades como la chilena pueden y deben realizar políticas públicas para aumentar su tasa de natalidad. 


\section{JUAN JACOBO ROUSSEAU RESPONDE POLÍTICAMENTE: EL NÚMERO SÍ IMPORTA}

Juan Jacobo Rousseau afirma que la asociación política nace de un pacto social entre hombres libres e iguales. Su objetivo no es la grandeza de una comunidad natural, anterior y superior a sus miembros, sino que es la conservación y la prosperidad de sus integrantes. En qué consiste esto es cosa en la que discrepan apasionadamente los pueblos. Sin embargo, el ginebrino nos propone un criterio simple y certero para evaluar si la asociación política cumple o no su misión. Leámoslo:

Y, ¿cuál es el signo más seguro de que se conserven y prosperan? El número y la población. No vayáis, pues, a buscar en otra parte tan disputado signo. El gobierno bajo el cual, sin medios extraños, sin colonias, los ciudadanos se multiplican, es infaliblemente el mejor. Aquel bajo el cual un pueblo disminuye y decae, es el peor. Calculadores, el asunto es ahora de vuestra incumbencia: contad, medid y comparad. (Rousseau, III, pág. 9)

No se trata que la Tierra de Nunca Jamás sea mejor que el quijotesco Imperio de Trapisonda porque la primera tiene más habitantes que el segundo. Pero es señal de que algo va mal cuando los habitantes disminuyen. Si dentro de las fronteras de una comunidad política se goza de prosperidad y salud, ¿por qué sus habitantes habrían de emigrar o renunciar a tener hijos? Podría ser por temor a una guerra. Por lo que una asociación política exitosa debe tener un ejército fuerte y aliados poderosos, cosa que preocupó a otro republicano como Maquiavelo (págs. 66-68). Agreguemos que otro motivo podría ser que los que emigran o deciden no tener hijos lo hagan pensando que serán aun más prósperos en otras latitudes. Por evitar esto, entre otras razones, Juan Jacobo Rousseau escribió largas páginas acerca del amor a la patria. Cuando se entibia el amor cívico, se agudiza la pasión mercantil o los Estados se hacen muy grandes, son gobernados por abusadores o se obsesionan por las conquistas, todo está perdido para la res publica. Por el contrario, promoviendo el patriotismo se evitaría la emigración o la deserción de sus numerosos hijos de la milicia ciudadana. Sea como fuere, para Juan Jacobo Rousseau era cosa evidente que "la residencia es señal implícita del consentimiento" (Rousseau, IV, pág. 2)1.

Africanos, asiáticos y latinoamericanos podrían decir que estarían mejor con menos niños. Rousseau escribió antes de la explosión demográfica. Un ciudadano europeo de hoy podría reclamar además que por mucho que Rousseau sea quien lo afirme,

1. Que el criterio demográfico no anda tan descaminado lo prueba la historia de un joven antropólogo de 25 años llamado Emmanuel Todd. Este advirtió en 1976 que las cosas no iban bien en la URSS, al ver algunos indicadores demográficos como el incremento de las tasas de mortalidad infantil. No lo tomaron muy en serio... hasta el 9 de noviembre de 1989. Hoy analiza los límites culturales -incluida la educación dentro de la familia- del sistema norteamericano. Véase Todd, E., La ilusión económica, Madrid: Santillana, 2001; y Todd, E., Después del Imperio. Ensayo sobre la descomposición del sistema norteamericano, Madrid: Akal, 2012. 
es contraintuitivo medir la prosperidad de una nación mediante un criterio numérico. Muchas sociedades desarrolladas ven disminuida su población nativa. No decrecen gracias a los inmigrantes. Las razones son muchas. Los avances de la educación, salud preventiva, salubridad y medicina curativa hacen disminuir la mortalidad y la presión por tener hijos. La industrialización y mecanización requieren de menos mano de obra. Las mujeres comienzan a tener acceso a una mejor educación, cambian sus expectativas de vida y su visión de la fecundidad (Larrañaga y Azocar, págs. 103-104). Aparecen programas de planificación familiar, activamente promovidos por gobiernos preocupados de la explosión demográfica. Producto de la liberación sexual, de la secularización y de la demanda de las mujeres por ingresar al mercado laboral, el aborto es legalizado y utilizado crecientemente como masivo método de control de natalidad. Agreguemos que la educación de los niños se hace más cara a la par que los hábitos de consumo más exigentes (Cerda, pág. 8). Menos niños y más población activa que pasiva genera un bono demográfico en que hay más riqueza que se produce y que se debe distribuir entre menos población. Hay además más dinero para educar a los niños y jóvenes. Las mujeres pueden tener trabajos remunerados que aumentan su libertad, los ingresos del hogar, disminuyen su precariedad en caso de desempleo de uno de los cónyuges y reduce las desigualdades (Larrañaga y Azocar, págs. 105-110). El proceso de individuación disminuye la importancia del matrimonio y la pareja deja de ser empresa compartida como ayer y pasa a ser convivencia regida por una democracia de las emociones (Giddens, págs. 65-79). El estadísticamente sólido matrimonio de ayer es reemplazado por el "amor líquido" de hoy (Bauman, págs. 15-57). Que ello haya sido malo para la felicidad de padres e hijos es cosa que está por verse (Ferry, págs. 84-102), pero es indiscutible que ha afectado la cantidad de hijos y la estabilidad de los vínculos. Así, se ha terminado por ingresar a una nueva etapa en que la tasa de crecimiento de población es cercana a cero o derechamente negativa.

Un Juan Jacobo Rousseau recargado podría contraatacar. Una población que disminuye tendrá problemas con su economía, su cohesión sociocultural y con su defensa militar.

Rousseau, citando a un socialdemócrata como Tony Judt, podría decir que si la economía europea se ralentiza y la emancipación de la mujer continúa, la declinante demografía europea podría traer "presagios de mal agüero para el estado de bienestar en los años venideros" (Judt, 2011, pág. 710). Si la población activa comienza a decrecer vis $a$ vis la tercera edad, crecientemente se hará imposible solventar los gastos previsionales, de vivienda, de transporte y salud pública que implican dar una merecida y segura vejez a los trabajadores y trabajadoras de ayer. Una sociedad con una gran tercera edad ahorra e invierte menos que una caracterizada por una mayor población activa. Por eso es que lo más probable es que el crecimiento económico se reduzca². El primer bono demográfico que se obtiene cuando baja la natalidad, durante el tiempo en que la población activa es superior a niños y tercera edad, supone, para aprovecharlo económicamente,

2. A menos que aumentemos su edad de jubilar, alentemos al adulto mayor a tomar nuevos trabajos y a ahorrar, aprovechando un segundo bono demográfico. Todo nada fácil de hacer (CEPAL, 18). 
capacidad de crear muchos y buenos empleos, cosa que no hacemos bien en América Latina (CEPAL, 17). Agreguemos que si la educación de los cada vez menos jóvenes sigue mejorando, el mercado presionará por bajar los salarios de los más calificados o se les inducirá a partir fuera del país que ya no necesita tantos y tan educados jóvenes para una economía ralentizada. Lo otro será que la demanda de mano de obra no calificada aumentará la presión por abrir las fronteras a los inmigrantes.

En la cuestión de la inmigración entraría al debate un conservador como Samuel Huntington. Este tendería a apoyar la importancia del criterio numérico de Rousseau. La inmigración masiva hacia Europa y Estados Unidos lo lleva a preguntarse si ello no es parte de un proceso de decadencia e invasión del Occidente, que se creyó vencedor en 1989. No es que Europa se islamice ni Estados Unidos se hispanice, sino que se transformen en sociedades escindidas en dos o más enmarañadas y enfrentadas civilizaciones (Huntington, 1997, págs. 235-246). De seguir este proceso, los norteamericanos se preguntarán cada vez más quiénes son (Huntington, 2007). La inmigración trae beneficios para el desarrollo y el crecimiento económico, señalan los contradictores al nativismo de algunos (Payne y Phillips, pág. 216). Pero más allá de las ácidas disputas académicas de las tesis culturalistas en torno a la unidad de Occidente, no es menos cierto que este debate ha penetrado la política y las audiencias de masas. Como lo prueban los actuales procesos electorales europeos, la xenofobia ha ido aumentado, en especial entre los jóvenes de bajo capital humano y los obreros que se sienten amenazados por los inmigrantes; aunque las explicaciones de las causas sociológicas del ascenso de la derecha radical europea no sean concluyentes (Norris, pág. 325). La cohesión sociocultural se ve tensionada cuando disminuye la población nacional y avanza la extranjera. Resurge el viejo nativismo ante extranjeros cada vez más numerosos. A este respecto puede ser problemática la forma según la cual Chile ha formado su identidad respecto de ciertos "otros": ingleses, franceses y norteamericanos versus bolivianos, peruanos y argentinos (Larraín, págs. 262-265). ¿Traerá eso problemas con la seguridad de nuestras fronteras?

Rousseau se preguntaría, pues, por las consecuencias militares de la transición demográfica. No es cosa segura vivir rodeado de países enemigos, cuya población se multiplica, mientras decrecen los candidatos a integrar la milicia. Es cierto que para ser numerosos los ejércitos contemporáneos no necesitan ser numerosos. Pero si un país tiene menos ciudadanos para defender sus fronteras, no debe quejarse que deberá invertir más dinero en soldados profesionales y en altísima tecnología militar (Ruiz, pág. 80).

Juan Jacobo Rousseau ha vencido en los países ricos. Más allá de los debates y distintas predicciones, que fallarán como casi siempre ocurre, la Unión Europea aconseja tomar medidas para enfrentar el envejecimiento de la población y sus gobiernos nacionales destinan ya una parte de su presupuesto en políticas de natalidad. Países tan distintos como la socialdemócrata Suecia, la laica Francia y la católica España dan beneficios tributarios, fiscales y sociales a las mujeres y/o parejas que deciden tener hijos.

Así, tener más hijos e hijas nacionales sí importa políticamente. 


\section{ARENDT, LÉVINAS Y ORTEGA Y GASSET AFIRMAN QUE GRACIAS AL NACIMIENTO HAY VIDA, LIBERTAD, ACCIÓN, PLURALIDAD E HISTORIA}

Más allá del debate político y socioeconómico acerca de los efectos de la disminución numérica de una nación, la pregunta que podríamos ahora abordar es filosófica. Es vital preguntarnos acerca del sentido de la natalidad. ¿Por qué las mujeres sufren las labores del parto y hombres y mujeres realizamos tamaño esfuerzo para ser padres? La respuesta puede ser bastante simple y la daría Hannah Arendt. Su conocida obra acerca de la vida activa la termina con lo siguiente: "El milagro que salva al mundo, a la esfera de los asuntos humanos de su ruina normal y "natural" es en último término el hecho de la natalidad, en el que se enraíza ontológicamente la facultad de la acción" (Arendt, 1993, pág. 266). La filósofa de la natalidad cita a judíos, griegos y romanos para afirmar que sin la incesante llegada de una nueva progenie, la ciudad muere y con ella la libertad y la acción de los muchos y concertados. El mundo está hecho por mortales y por ello se marchita. El nacimiento de una nueva generación lo mantiene vivo. Esto es también especialmente claro para un intelectual como Carlos Fuentes. Este advierte el sentido de la natalidad y acción humanas viendo a los antiguos mayas. Estos sabían muy bien que si ellos dejaban de reproducirse y de trabajar, la exuberante naturaleza que los rodeaba terminaría por tragar sus ciudades y su civilización por morir (Fuentes, págs. 99-106). La filosofía nació con el color de los muertos, pensando la muerte. Pero ella también ha abordado el origen inmediato de la vida, que es el nacimiento. Es Heidegger frente a frente a dos discípulos aventajados: Arendt y Lévinas.

Heidegger es el filósofo de la mortalidad. Para él, los seres humanos somos arrojados a la existencia. La angustia surge al tomar conciencia que estamos suspendidos sobre la nada. De ella venimos y a ella vamos. Más aun, sabemos que lo único necesario en nuestra vida es la muerte. Vieja sabiduría agustiniana. Somos seres intermedios entre los brutos y los ángeles. Ellos, irracionales y mortales. Aquellos, racionales e inmortales. Nosotros animales que sabemos vamos a morir (Agustín, IX, pág. 3). Es para angustiarse. Albert Camus lo dice a través de un sereno Calígula, quien proclama "una verdad muy simple y un poco tonta, pero difícil de descubrir y pesada de llevar: -los hombres mueren y no son felices-" (Camus, pág. 402). Para Heidegger esta es la cuestión existencial clave. Una vida inauténtica es pretender olvidarse que vamos a morir; entreteniéndonos con las cosas, entregándonos a las relaciones sociales triviales o viviendo en el constante gozo de los placeres estéticos. Una vida auténtica, por el contrario, es el aceptar la tragedia del existir, viviendo con la constante presencia del destino último que es la nada, a través de la muerte. Nos develamos como seres-para-la-muerte. Sin embargo, Hannah Arendt se pregunta por qué no partir nuestra reflexión por el sentido de la existencia desde esa otra nada que antecede al inicio de la vida propia. ¿Si fuésemos seres-para-la-vida? ¿No nacemos a ella?

Hannah Arendt es la filósofa de la natalidad. Para ella, la persona es aquel ser que es capaz de comenzar algo nuevo. Con cada nacimiento un nuevo comienzo entra en el mundo. Este salva la vida humana de la condena sin salvación que sería el lapso de la vida en su loca carrera a la muerte, a la destrucción y ruina. La acción es iniciar algo y 
todo comienza con el nacimiento. Además el nacimiento es el origen de la singularidad irrepetible de cada hombre y es el mejor antídoto contra el totalitarismo, el exterminio, la masificación y el considerar la vida humana como superflua, el mal radical (Arendt, 1987, pág. 707); "Ningún hombre es idéntico a otro que haya vivido, que viva o que vaya a nacer en el futuro" (Arendt, 1993, pág. 22). El nacimiento es un milagro pues sobre el silencio y la oscuridad que domina el Universo desde el principio de los tiempos surge lo absolutamente improbable: un cuerpo consciente y libre. Así pues, Hannah Arendt toma distancia de la analítica existencial de su maestro. Somos seres natales y mortales. Somos seres-nacidos-para-la-acción y ella surge con el nacimiento de hombre y mujer, "hombre y mujer los creó" (Gén., I).

Los hombres, aunque han de morir, no han nacido para eso, sino para comenzar algo nuevo. Initium ut esser homo creatus est; 'para que hubiera un comienzo fue creado el hombre', dijo Agustín. Con la creción del hombre, el principio del comienzo entró en el mundo, lo cual naturalmente, no es otra forma de decir que, con la creación del hombre, el principio de la libertad apareció en la tierra. (Arendt, 1995, pág. 107)

Emmanuel Lévinas piensa la paternidad tras sus lecciones con Heidegger en Alemania. En el París aún no ocupado por el nazismo, nos cuenta que pronunció una conferencia sobre la filialidad que tituló "Más allá de lo posible". Acababa de ser padre y se enfrenta a su maestro.

La paternidad es una relación con un extraño que, aun siendo el otro, es yo. La relación del yo con un yo-mismo que es, sin embargo, extraño a mí. En efecto, el hijo no es simplemente mi obra, como un poema o como un objeto fabricado, no es tampoco mi propiedad. Ni las categorías del poder ni las del tener pueden indicar la relación con el hijo. Ni la noción de causa ni la noción de propiedad permiten captar el hecho de la fecundidad. Yo no tengo a mi hijo, yo soy, de alguna manera, mi hijo. (Lévinas, pág. 66)

Ser padre es comprender ese misterio en que el otro es radicalmente otro y, sin embargo, es, de alguna manera, yo. El hijo es el porvenir más allá de mi propio ser. Lévinas, al igual que Hannah Arendt, ve en el nacimiento que posibilita la paternidad el principio de la libertad en el existir pluralista. Padre e hijo son y no son un mismo ser. En ese "yo soy mi hijo" hay multiplicidad y trascendencia. El hijo no es un acontecimiento que nos pasa. El padre sabe que ese otro es una persona que me une en una relación que no es compasión o simpatía, "por la cual puedo ponerme en el lugar del hijo; yo soy mi hijo por mi ser, y no por la simpatía..." (Lévinas, pág. 67). Mujer, hombre e hijo son "hueso de mis huesos, carne de mi carne" (Gén. II). Es otro y yo. Misterio. La paternidad es la forma como el animal laborans, mujer y hombre, vencen la muerte. Al edificar casas y escuelas los padres, ahora como homo faber, vuelven a derrotar la muerte creando el mundo para ellos y sus hijos. Pero no basta con la renovación de la vida biológicamente considerada; la cultura humana y de sus naciones debe continuar dejando memoria 
inmortal allí donde llegan. Por ello no solo arropamos y alimentamos a nuestros hijos e hijas. Además los educamos pues, en caso contrario, el mundo y sus civilizaciones morirían. El mundo, "porque continuamente cambian sus habitantes, corre el riesgo de llegar a ser tan mortal como ellos" (Arendt, 1996, pág. 204). Los griegos llamaban a los jóvenes "los nuevos", a los que debemos introducir en un mundo, viejo y mortal, que les es extraño. Introducirlos en él para que, haciendo lo propio, lo cuiden y transformen para los tiempos por venir. Es en el ciclo de las generaciones que el mundo no solo se perpetúa, sino que se renueva. Por eso la divinidad del nacimiento en cuanto tal pues "la salvación potencial del mundo reside en el hecho de que la especie humana se regenera constate y eternamente" (Arendt, 1993, pág. 266). Por eso cada vez que nace un niño la muerte es vencida, el mundo es renovado y la historia nunca finaliza. Siempre recomienza antes de convertirse en cenizas.

José Ortega y Gasset es el filósofo de las generaciones y agrega un nuevo jalón en esta filosofía de la natalidad. Este observa que "el hecho más elemental de la vida humana es que unos hombres mueren y otros nacen, que las vidas se suceden" (Ortega y Gasset, pág. 38). Toda vida humana está encajada entre la que le precedió y la que le sucederá. Vidas humanas que ingresando y actuando van cambiando la estructura del mundo. Pues el hombre constantemente hace mundo, forja horizontes. Es cierto que el hombre, en un principio, cuando nace, va absorbiendo las convicciones de su tiempo y el espíritu de su época. En la niñez y juventud no hace más que aprender, recibiendo las noticias del mundo, educándose, conversando, leyendo. Lo observa todo con avidez, entusiasmado y extasiado, fuera de sí. Pero llega un momento que el joven se hace adulto y se lanza a vivir por su cuenta, a hacer también el mundo. Lo hace solo con los miembros de su generación, que nació en una misma zona de fechas y en un mismo espacio. Serán los españoles de 1898, por ejemplo, o los chilenos de 1973. Entonces se enfrentarán a sus mayores, los que gobiernan el mundo. Pero lo hacen con las ideas y técnicas de su tiempo, que no ya no son las de la nueva generación. De ese anacronismo esencial, del hecho que las generaciones de jóvenes, adultos y viejos son contemporáneas, pero no coetáneas, surge el desequilibrio que mueve y cambia la historia, la hacer rodar y fluir. Las generaciones no se suceden, se solapan. En torno a las mismas cosas y temas, actuarán en distinto sentido y polemizarán. Ortega y Gasset recuerda a Plutarco:

Los viejos: Nosotros hemos sido guerreros muy fuertes.

Los jóvenes: Nosotros lo somos: si tenéis ganas, miradnos a la cara.

Los muchachos: pero nosotros seremos mucho más fuertes todavía. (Ortega y Gasset, pág. 46)

Para Hannah Arendt el nacimiento es un milagro, pues en él todo vuelve a comenzar en forma riesgosa, promisoria, abierta, única e irrepetible (Kristeva, pág. 59). Los seres humanos forman generaciones y se agrupan en naciones que enriquecen la pluralidad y riqueza del mundo. Cuando una generación desaparece o una cultura se muere, es el mundo el que pierde en diversidad. Por otro lado, Emmanuel Lévinas nos recuerda que 
no nacemos para morir. En nuestros hijos somos seres-para-más-allá-de-la-muerte. Esta es la conmoción de la paternidad y la maternidad. Por último, José Ortega y Gasset nos recuerda que cada nueva generación está llamada a hacer un nuevo mundo, sobre los hombros de las generaciones anteriores, poniendo en movimiento a una historia que no dejará jamás de renovarse. En suma, sin la natalidad no habría vida, libertad, acción, pluralidad ni historia.

\section{AFIRMACIONES POLÍTICAS PROSPECTIVAS: APOSTAR POR LA ANSIADA FRATERNIDAD, EL PATRIOTISMO CÍVICO Y UNA NUEVA MASCULINIDAD}

Juan Jacobo Rousseau no hubiese necesitado ver los horrores cometidos en su nombre por su discípulo Robespierre. Ya sabía de los monstruos, muerte y agonía que pueden crear pacíficas instituciones promovidas por hombres de buena voluntad. Levantando la vista de sus escritos ve fuego y llamas, campos desolados y aldeas saqueadas. Escribe entonces: "De lo más hondo de mi corazón surge piedad e indignación. Ah, filósofo, ven y léenos tu libro en el campo de batalla" (Keane, pág. 11). Son evidentes los temores que puede provocar este ensayo. Sobre los bellos cimientos de la vida, la libertad, la acción, la pluralidad y el progreso podría estar edificándose una nueva cárcel para la mujer, sacrificada en un renovado natalismo patriarcal. Un segundo temor surge si creemos que el elogio de la natalidad humana puede terminar por hacer insostenible la vida en nuestro planeta Tierra (a la que ya le robamos el nombre humano, que viene de humus, tierra). Los sistemas naturales ya están agobiados por la explosión demográfica y la industrialización bajo el Antropoceno, que podría ser la última edad geológica que conozca la Humanidad (Sachs, pág. 101)33.

\section{NATALIDAD, MUJER, SOCIEDAD Y NUEVA MASCULINIDAD}

El elogio de la natalidad en Hannah Arendt podría ser usado para fundar el retorno del patriarcado. Eso iría contra la revolución más importante del siglo XX: la irrupción de la mujer, a través de la democracia, en la vida pública (Bobbio, 1984, pág. 49). Para intentar evitar caer en un patriarcalismo recargado, por antihumanista y contrario a la emancipación femenina, es bueno someterse a la lectura de una mujer llamada Julia Kristeva. Ella es estudiosa del genio femenino en Hannah Arendt. Kristeva recuerda un pasado abominable, en que se creía que la vida de las mujeres no tenía más sentido de ser "una suerte de ganado"; o en que Joyce atribuyó el tiempo a los hombres y reservó a las mujeres el espacio-especie, y Baudelaire se burló del aspecto pueril de la maternidad (Kristeva, págs. 13-14). Kristeva elogia el genio de Hannah Arendt, que vio en el naci-

3. Hay otros que no podré tratar. La oda de la natalidad de los nacionales por temor al extranjero: natalismo y nativismo. La segunda es la promoción de la natalidad por odio al viejo: natalismo y gerontofobia. 
miento el origen de la libertad como autocomienzo. Cada uno debe amarse sabiendo que nadie escapa a su nacimiento. Por ello asimilarse es lo mismo que querer renacer y, como lo dijera Arendt, "no se nace por segunda vez" (Kristeva, pág. 84). Justamente Arendt nunca pretendió ser distinta de lo que era, judía y no gentil, mujer y no hombre. Para ella lo femenino es la piedra fundamental en la que se apoya la pluralidad y la acción. Como recordó muchas veces, el Génesis afirma aquello de "Él los hizo varón y hembra". (Arendt, 1993, págs. 33-34).

Hannah Arendt -y Julia Kristeva lo sabe bien- no fue una feminista. Pero tampoco fue una promotora de la maternidad irreflexiva. Como una vez le explicó a su amigo Hans Jonas, ella nunca tuvo hijos propios pues "cuando éramos bastante jóvenes para tener hijos, no teníamos dinero, y cuando tuvimos dinero ya éramos demasiado viejos para tenerlos" (Young-Bruehl, pág. 345). Su marido Heinrich Blücher agregó que "decidimos no tener hijos en una época como la presente. El hecho nos entristece, pero se debe valorar la responsabilidad hacia los que pueden ser víctimas inocentes" (YoungBruehl, pág. 345). En consecuencia, la propia biografía de Hannah Arendt nos enseña que su elogio de la natalidad no puede ser base para concebir y acoger vidas humanas en forma irresponsable. Ella no pudo tener hijos por problemas económicos y por un mundo convulsionado por la guerra. La historia hoy se repite. Entonces hablar $-\mathrm{y}$ con ella- de lo que está pasando con la natalidad es camino muy sinuoso, que nos lleva a transitar por aspectos de nuestra sociedad que no queremos ver y asumir costos que no deseamos pagar. Volveremos sobre esto en el epílogo.

Para que la maternidad sea vivida como realización de la femineidad debemos insistir que ello supone apoyo cada vez más activo de la sociedad en general y del varón en particular. Para que la natalidad sea expresión esencial de la vocación femenina, sin sacrificar la igualdad esencial de hombre y mujer ni la pareja humana como base de la acción humana, es necesario impulsar el cambio en la masculinidad tradicional. La pareja es una unidad funcional. Si se transforma una parte y no la otra, se quiebra. De hecho, los varones están cambiando. Los hombres tienen menos hijos, con ingresos económicos inferiores y empleos inestables, comparten sus vidas con mujeres que trabajan fuera del hogar y observan el avance de las ideas igualitarias. Las formas de adaptarse a la nueva situación son múltiples. Algunos se separan, huyen del compromiso y, tras el narcisismo individualista, los solteros y separados sufren la soledad y tristeza, de peor modo que las mujeres en igual situación (Castells, págs. 260-261). Otros, como lo describe Marina Subirats, apuestan por el retorno al patriarcado y al machismo que ejerce autoritarismo y control sobre la mujer e hijos, especialmente las hijas (Castells y Subirats, pág.134). Aparece también el ejecutivo hedonista, refinado y abierto a lo femenino, exitoso y consumista, que rehace la vieja masculinidad. No falta la masculinidad centrada en sí misma, en el cultivo del cuerpo y el desarrollo de la cotidianidad, cuidado y ternura con matices gay. Finalmente, la masculinidad multidimensional, que no teme incluir rasgos tradicionalmente femeninos, como cuidar con ternura al bebé, dar de comer al padre enfermo, limpiar, apostar por causas solidarias, dejar de competir por la jerarquía y asumir las tareas domésticas, simplemente porque hay que hacerlas, con el encanto y molestia de todo trabajo (Castells y Subirats, pág. 135). Castells cree 
-así lo esperamos- que esta última opción es elegida por la mayoría de los hombres: "la solución a largo plazo más aceptable y estable es renegociar el contrato de la familia heterosexual. Ello incluye compartir las tareas domésticas, la participación económica, la participación sexual y, sobre todo, compartir plenamente la paternidad" (Castells, pág. 261).

En suma, si queremos aumentar nuestra natalidad, especialmente entre las mujeres que trabajan fuera del hogar, la sociedad chilena deberá ayudar a las familias y a los hombres a ingresar en la vida doméstica. En caso contrario, la mujer moderna sufrirá una doble jornada de trabajo -el remunerado y el doméstico- que atentará contra sus derechos y disminuirá la natalidad, como ocurre en España o Italia (Marcel y Rivera, 2008, pág. 171); la natalidad no será de nuevo el sepulcro de la emancipación femenina, o no será.

\section{LA FRATERNIDAD REDIMIDA Y UNA HUMANIDAD RECONCILIADA CON LA NATURALEZA}

A Umberto Eco le preocupa el futuro de un planeta abarrotado de gente. Por ello una reflexión-predicción de Eco es especialmente provocativa:

Fin de la experiencia de la fraternidad. Para afrontar el crecimiento de la población del globo, no habrá más remedio que adoptar medidas al estilo chino: no más de un hijo por familia. Los conceptos como hermano y hermanas quedarán sepultados en la memoria, un poco a la manera del hada o del ogro de los cuentos de nuestra infancia (...) Naturalmente la fraternidad sobrevivirá como metáfora, pero será difícil explicar a un niño lo que significa amar a una hermana o a un hermano. (Carriere, Delumeau, Eco y Gould, 1999, pág. 282)

Si me permite una acotación personalísima, proviniendo de una familia de cuatro hermanos y habiendo fundado una de igual número, no puedo dejar de sentirme provocado por el gran semiólogo. Sé muy bien que detrás de Caín y Abel, y Rómulo y Remo, se esconde la descripción del lado oscuro de los hermanos que compiten por el cuidado y bienes de sus padres. Pero me es imposible aceptar que el amor de los hermanos sea parte del museo de los recuerdos. Sobre todo si no acepto la premisa en la que se basa la conclusión. Reventaremos el globo terráqueo si seguimos teniendo más hermanos. No. Lo que hará explotar el planeta es consumir como unos irresponsables dirigidos por la codicia, el egoísmo y el consumismo de una sociedad capitalista extrema. Esa que domina en los escaparates y calles de Hong Kong, Mumbay, Dubai, Londres, Nueva York, Sao Paulo o Santiago de Chile. En vez de renunciar a la fraternidad, ¿no sería mejor consumir un poco menos? Se nos viene una hecatombe global si doce mil millones de seres humanos quieren vivir como lo hacen los norteamericanos. En el país del norte hay 800 autos por cada mil habitantes; en China 18 por cada 1000. Si los seiscientos millones de chinos e indios de clase media quieren tener igual 
proporción de los actuales autos, adiós planeta (Sachs, pág. 113). Por cierto, esta solución aparece como pura estupidez para quienes gobiernan el mundo describiendo y siguiendo las leyes que lo subyugan. Frenar la población, especialmente en los países pobres, es cosa más fácil que andar predicando sandeces acerca de la austeridad o de la ética del consumo.

Al decir de un iracundo Giovanni Sartori, una de las mentes políticas más formidables del realismo político italiano del siglo XX, la bomba demográfica se desactiva con la píldora anticonceptiva. Eso es fácil de promover y no imposible de hacer, como es convencer a los pueblos ricos de dar marcha atrás en su bienestar. "Tanto más cuanto que los ricos viven en democracias en las que tienen voz y voto, y por tanto en países en los que el que predica semejante pobreza, o algún tipo de renuncias al bienestar, pierde las elecciones" (Sartori, 2003, pág. 24). Sin embargo, por todas las razones que vimos en el segundo acápite, este realismo es de piernas cortas. El propio Sartori debiera reconocerlo cuando escribe alarmado acerca del multiculturalismo y la inmigración en su acomodada Italia (Sartori, 2001). En consecuencia, es posible e imprescindible proponer otros realismos, nuevas concepciones de vida y mejores tecnologías.

El otro realismo afirma que nuestro planeta puede con nuestras necesidades, no así con nuestras codicias. Bastaría que la población más rica del planeta -270 millones de personas- reduzca razonablemente su nivel de consumo de energía para dar una vida más digna a más de 2500 millones de seres humanos (Díaz, pág. 19). Gandhi no decía ingenuidades cuando defendía que todos podíamos ser hermanos -fraternos-, escribiendo que "la naturaleza produce en cantidad suficiente lo que necesitamos para cada día, y si cada uno se contentara con lo que necesita, y nada más, no habría más ya pauperismo en el mundo y nadie se moriría de hambre. Si seguimos manteniendo esta es porque somos ladrones" (Gandhi, pág. 86). Requerimos nuevas ideas y modos de vida para enfrentar la explosión demográfica, el daño medioambiental y el desafío científico-tecnológico (Hobsbawm, pág. 576). Que esto sea imprescindible para filósofos, religiosos e historiadores no lo hace necesariamente posible de realizar. Sin embargo, la política y la economía de hoy señalan que este desafío es posible de abordar. El economista del desarrollo contemporáneo, Jeffrey Sachs, escribe que los gobiernos del mundo rico deben y pueden realizar enormes esfuerzos en tecnologías verdes. Que junto a políticas internacionales de planificación familiar, la Humanidad puede realizar inversiones que vayan hacia una economía verde que acoja a doce mil millones de humanos (el doble que la actual población). De hecho, un norteamericano medio emite 20,6 toneladas de dióxido de carbono contra 9,8 toneladas de un habitante alemán. Es decir, se puede contaminar menos sin sacrificar calidad de vida... ni fraternidad (Vásquez, pág. 6). Luego, no se trata solo de buenas intenciones. Agreguemos que hemos sido capaces de acabar con el agujero en la capa de ozono (Sachs, págs. 161-163). Desde 1900 la Humanidad ha aumentado la producción de comida per cápita en un cincuenta por ciento; es la revolución verde (Ridley, pág. 145). La conclusión es que podemos ser racionalmente optimistas si hay voluntad política, apoyo económico y científico e involucramiento activo de la comunidad organizada. La natalidad no es la tumba del planeta Tierra. 


\section{EPÍLOGO ABIERTO: SER PADRES EN EL CHILE INDIVIDUALISTA Y UTILITARISTA DE HOY}

Resumamos entonces. Juan Jacobo Rousseau nos enseña que el número sí importa. Una población que disminuye tendrá sobresaltos con su economía, su cohesión sociocultural y defensa militar. Hannah Arendt, Emmanuel Lévinas y José Ortega y Gasset nos recuerdan que el nacimiento es un milagro de naturaleza divina que permite la vida, la libertad, la acción, la pluralidad y el movimiento de la historia. Hemos argumentado, además, que una mayor natalidad no necesariamente debe ser al costo de volver al patriarcado ni de expoliar definitiva y fatalmente el planeta Tierra. Los chilenos creen en ello. La Encuesta Bicentenario 2009 demostró que eran afirmaciones altamente compartidas respecto de los hijos e hijas las siguientes: "Producen felicidad" (92\%), "Nos ayudan a crecer como personas" (86\%), "Mantienen la familia unida" (68\%) y "Fortalecen la relación de pareja" (61\%). Sin embargo, Chile cuenta con una baja tasa de natalidad y su población comenzará a disminuir cuando alcance los 20 millones de habitantes en unos pocos años más.

Insistamos que el que dejemos de crecer e incluso disminuyamos en población no solo va en contra de lo dicen querer los chilenos. Además puede convertirse en un cuello de botella para nuestro crecimiento económico y cohesión sociocultural. La población se envejecerá. Se ha calculado que al año 2050 habrán 130 personas de la tercera edad por cada 100 jóvenes (Cerda, pág. 12). Al año 2009 se calculó que, aunque bajará la presión sobre el financiamiento en educación producto de la transición demográfica chilena, la duplicación de adultos mayores -de un 11,5\% al 24,2\% en 2030- significará un aumento del gasto público en salud desde el 2,7\% del PIB en 2005 hasta 3,6\% del PIB en 2030. La seguridad social subirá desde 6,2\% hasta 7,4\% del PIB en el mismo período. El efecto conjunto de estos factores será de un $2 \%$ del PIB en gasto público social adicional (Marcel y Rivera, 2009, págs. 301-304). Ello implicará un enorme desafío socioeconómico y cultural. Bolivia y Perú tienen tasas de natalidad más elevadas que la chilena (CEPAL, pág. 13). Ello implicará un enorme desafío socioeconómico y cultural. Manteniendo nuestros vecinos sus actuales tasas de natalidad, más elevadas que la chilena, al año 2045 habrá 50 millones de argentinos, 38 millones de peruanos y 16 millones de bolivianos (Ruiz, pág. 73). El problema se agudiza en nuestras zonas extremas: Arica (186 mil habitantes) y Puerto Williams (3000 habitantes) pierden fuerza ante el empuje de Tacna (252 mil habitantes) y Ushuaia (59 mil habitantes). La ausencia de una poderosa política de Estado grita al cielo por sus nocivas consecuencias. Los chilenos y chilenas de las zonas extremas nos lo recordaron durante los años 2011 y 2012. La inmigración será una necesidad nacional, la política territorial un imperativo y una activa política exterior una prioridad absoluta (como debieran serlo siempre, por cierto).

Tanto las encuestas de opinión como estudios más sofisticados demuestran que un principalísimo problema para elevar nuestra natalidad es la disociación entre reproducción sexual y producción económica. Según la Encuesta Bicentenario 2009, sobre el $50 \%$ de las encuestadas señalan que tener más hijos dificulta que la mujer trabaje; que los niños son difíciles de mantener y que criar niños conlleva muchas preocupaciones 
y responsabilidades. Un 43\% de los chilenos declararon que la sociedad no apoya a las mujeres para tener hijos. En la Encuesta del Bicentenario del año 2011 solo un 9\% por ciento de las mujeres declaró que le gustaría tener solo un hijo; pero un 27\% está en esa situación. Un 35\% por ciento de ellas dijo querer como número ideal dos hijos y un $27 \%$ optó por tres hijos (la familia de hoy es de poco más dos hijos). Sin embargo, el costo de la educación de los niños es la principal razón para limitar su número. Además, a las mujeres en edad fértil se les ponen dificultades para ingresar a ciertos trabajos de mejor calidad, los que deberán abandonar al ser madres. Quisieran amamantar a sus hijos siete meses o más; pero no pueden hacerlo, sobre todo las de ingresos más bajos. En el cuidado de los niños los abuelos ayudan mucho más que jardines infantiles y salas cunas, en cuya calidad no se confía. En suma, la familia es motivo de tensiones.

Gabriel Salazar lo expresa con fuerza en medio del año de las protestas de las clases medias por la educación chilena. El Premio Nacional de Historia sostiene que las familias chilenas se endeudan en altos montos y con créditos con intereses desmedidos para pagar educación, vivienda, mobiliarios, salud y bienes suntuarios. "Hasta que reventamos: el 45\% de los chilenos padece de depresión seria; el 58\% de los niños que nacen en Chile son 'huachos'; el 35\% de las madres son solteras; la tasa de nupcialidad ha caído un 60\% en 12 años, las separaciones se duplican...Los femicidios también" (Salazar, pág. 8). Podemos enfrentar esta situación y superarla. Pero si queremos más niños y niñas y mejores y más estables parejas debemos invertir en ello. "Dónde está tu tesoro, ahí está tu corazón". Se deben concebir, aprobar, ejecutar y evaluar políticas públicas que hagan posible una mejoría en nuestra tasa de natalidad. No basta la voluntad, juicio y poder de los eventuales padres. Se requieren una serie de cambios en nuestras ciudades y sociedades: áreas verdes, medios de transporte baratos y eficientes, vecindarios amigables, guarderías, salas cunas y educación preescolar para todos, junto a una educación básica y media pública de calidad y gratuita, flexibilidad de horarios laborales que permitan la compatibilidad entre ser padres y trabajadores, reformas curriculares, Código de la Familia y mediación, feminización de nuestras instituciones políticas y empresariales; subsidios pro-paternidad, etc. (Valenzuela, Tironi y Scully, 2006). Estas son formas concretas de promover la natalidad sin sacrificar a la mujer ni la felicidad de nadie. Por el contrario. Es un camino costoso y sinuoso que han recorrido, con mediano éxito, otras naciones como Francia y Suecia. Pero se puede. De hecho acabamos de aprobar una nueva legislación de pre y postnatal y se anuncian becas y alivios a endeudados padres. Pero aun haciendo todo esto no basta. Es una cultura la que debe modificarse.

Siendo muy importantes las reformas legales e institucionales presentadas en el párrafo anterior, la cultura es la llave maestra para abrir de par en par las puertas de una nueva era. Finalmente, una nación que favorece la natalidad, acogiendo a infantes y personas de la tercera edad, "costosos e improductivos", supone una cultura superior a la que hoy nos habita, tan marcada por el individualismo y la búsqueda de la utilidad. El capitalismo supone la mercantilización de todo y"desde el punto de vista del análisis económico, los niños son bienes de consumo de alto precio que rápidamente se están volviendo más costosos" (Thurow, pág. 45). Seamos más sinceros aún. Un niño implica un enorme sacrificio a los proyectos privados y públicos -empresariales, profesionales, 
académicos, políticos, militares o artísticos- de sus progenitores. No es raro que la mitología griega esté plagada de historias de envidias y celos entre hijos y padres. Cronos devorando a sus hijos para luego ser derrocado por sus descendientes -Zeus, Hades y Poseidón- y encerrado en el Tártaro. Todo padre ha sentido ese horrible sentimiento nocturno de querer tirar por la ventana al bebé insomne. Las depresiones de las madres y las "viriles" huidas de los padres hablan bien de esto. Parafraseando indebidamente a Simone de Beauvoir, podríamos decir que algo de cierto tiene aquello que la paternidad supone el sacrificio del individuo en aras de la supervivencia de la especie. ¿Escribo algo que no sepa el lector? Para enfrentar este último e inesperado giro de este ensayo, es bueno terminar rodeado de palabras que forman parte de valientes páginas escritas contra una cultura que abandona a sus retoños y abuelos en aras del "sí mismo", de la "autoestima", del "proyecto existencial" o de la "felicidad personal" (como si existiese algo así, como eso: felicidad exclusivamente personal).

Debemos cuidar a nuestros progenitores, y para ello arremeter contra el utilitarismo. Pues nada de lo que se ha escrito en pro de la natalidad debe leerse como una condena a la ancianidad. Cicerón inspira cuando bellamente presenta la vejez, tras una vida bien vivida, rodeada de jóvenes que escuchan la voz fuerte del anciano, cargada de experiencia y sabiduría, como una extraordinaria etapa de la vida. El viejo que al término de sus días ha hecho de su vida algo digno de ser contado, posee algo que un joven quizás no tendrá jamás. ¡Finalmente, todos queremos llegar a viejos! "Cuando un anciano se muere, es una biblioteca entera la que se quema", dice el refrán africano. Dos mil años después Norberto Bobbio escribe su De senectute. Tiene 80 años y está lleno de pesimismo. Critica ácidamente a su antecesor en el diálogo. Bobbio le exige a Cicerón que diga las cosas por su nombre. Ser anciano consiste en un descenso, lento, continuo e irreversible, hacia ninguna parte. Hace falta mucho valor para ingresar a ese mundo en que la solitaria viuda de 85 años escribe: "No puede imaginarse cómo es esta espera de nada. No se puede. Yo no lo sé explicar. Me entran ganas de llorar. Nuestra vida es como si nunca hubiera existido y yo, poco a poco, me estoy olvidando de todo, y cuando me vaya olvidando de todo, moriré y nadie sabrá de mí" (Bobbio 1997, págs. 36-37). Si todo es consumo, derroche y trabajo, ¿quién puede alegrarse de llegar a la tercera edad? Cuando la vida se reduce a estudiar para trabajar, trabajar para producir el máximo de bienes y servicios al menor costo posible para luego consumir en un escaso tiempo libre la mayor cantidad de bienes, no parece haber mucho espacio para la tercera edad. Si lo anterior es cierto, ¿qué puede aportar a una sociedad un viejo pobre y jubilado que ya no puede trabajar ni consumir? ¿Cómo se soporta bien a personas de la tercera edad que gastan más de los ingresos que contribuyeron a generar? Peor aun si no se tuvo hijos o ellos le abandonaron sin honrarlos. En consecuencia, si queremos que nuestros viejos tengan una mejor vida junto con nuestros niños, no edifiquemos una sociedad individualista y materialista.

Podemos abandonar la cultura del narcisismo que nos oprime y vivir la paternidad de diversa manera. Christopher Lasch describe con pluma ácida la sociedad norteamericana contemporánea (Lasch, 1996). Para el sociólogo norteamericano vivimos bajo la égida del individualismo burgués dominado ya no por la culpa sino que por la ansiedad. 
Ansiedad de reconocimiento y de fama; ansiedad al ser controlado por la pasión dominante de vivir el momento: ansiedad de vivir para uno mismo, no para nuestros predecesores ni para la posteridad; ansiedad de antojos que no tienen límites pues se "exige gratificaciones inmediatas y vive en un estado de deseo inagotable, perpetuamente insatisfecho" (Lasch, 1990, págs. 17 y 23). Que el bien común y el amor de los demás sean inmolados en este moderno monte Moriah no nos debe extrañar. Una de sus víctimas sacrificiales es la familia que debiera, para el crítico norteamericano, ser cuidada como "refugio en un mundo despiadado" (Lasch, 1990).

Luc Ferry, un filósofo francés, republicano y ateo, coincide en ello. Ferry cree que en los tiempos de individuación, globalización y deconstrucción, donde ya nada parece sólido ni verdadero, es en la familia donde redescubriremos lo sagrado y trascendente. Lo sagrado es aquello por lo cual vale la pena sacrificarse (incluso la vida). Lo trascendente es la creencia en algo que es externo y superior a mí. Para Ferry es evidente que muchos padres y madres están dispuestos a sacrificarse por sus hijos e hijas, pues los aman más allá del individualismo posesivo. En la familia alcanzamos los más altos grados de amor y afecto (Ferry, págs. 22 y 82). A pesar de nuestros egoísmos y miserias, es en la familia donde la persona "más que en ninguna parte, encuentra razones para salir de sí misma, para amar y respetar, para admirar a los demás y sentirnos obligados con ellos" (Ferry, pág. 109). Con todos sus cambios, la familia desestructurada, arrastrada más allá del matrimonio o sin duda recompuesta, menos hipócrita, más auténtica y más atractiva que en ningún otro momento de su historia, se alza como espacio de formas de solidaridad, más allá de toda competencia, individualismo y materialismos ambientes.

Bobbio, Lasch y Ferry nos ayudan a fundar mejor esa esperanza que nos falta y que debe volver a reunir a niños, padres y abuelos en una sociedad fuerte y cohesionada en que las palabras del poeta tengan sentido y razón:

\section{¡Qué dulce es entrar en el sueño de la muerte arrullado por la plegaria de un hijo! \\ Ese es el verdadero réquiem.}

Friedrich Schiller

\section{REFERENCIAS BIBLIOGRÁFICAS}

Arendt, H., La condición humana, Barcelona: Paidós, 1993.

— De la historia a la acción, Barcelona: Paidós, 1995.

—- Entre el pasado y el futuro. Ocho ejercicios sobre la reflexión politica, Barcelona: Península, 1996. Bauman, Z., Amor líquido. Acerca de la fragilidad de los vínculos humanos, México: Fondo de Cultura Económica, 2005.

Bobbio, N., El futuro de la democracia, México: Fondo de Cultura Económica, 1984.

— De senectute, Madrid: Taurus, 1997.

Camus, A., Calígula, en: Obras Escogidas, Santiago de Chile: Editorial Andrés Bello, 1991. 
Carriére, J.C., Delumeau, J., Eco, U. y Gould, J., El fin de los tiempos, Barcelona: Anagrama, 1999. Castells, M., La era de la información, Vol. 2. El poder de la identidad, Madrid: Alianza Editorial, 1998.

Castells, M., Subirats, M., Mujeres y hombres. ¿Un amor posible?, Madrid: Alianza Editorial, 2007.

CEPAL, Tendencias demográficas y protección social en América Latina y el Caribe, Santiago de Chile: CEPAL, 2008.

Cerda, R., "Cambios demográficos y sus impactos en Chile", en Revista de Estudios Públicos, No110, Santiago de Chile: Centro de Estudios Públicos, 2008.

Díaz, C., Ilustración y religión, Madrid: Ediciones Encuentro, 1991.

Donoso, E., "Descenso de la natalidad en Chile: Un problema país", en Revista chilena de obstetricia y ginecología, V. 72, No2, Santiago de Chile, versión online, ISSN. 0717-7526, 2007.

Ferry, L., Familia y amor. Un alegato a favor de la vida privada, México: Taurus, 2008.

Fuentes, C., El espejo enterrado, México: Fondo de Cultura Económica, 1992.

Gandhi, M., Todos somos hermanos, Madrid: Librería Dersa, 1998.

Giddens, A., Un mundo desbocado: Los efectos de la globalización en nuestras vidas, España: Taurus, 2000.

Hobsbawm, E., Historia del siglo XX, Buenos Aires: Crítica, 1998.

Huntington, S. P., El choque de civilizaciones y la reconfiguración del orden mundial, Barcelona: Paidós, 1997.

— ¿Quiénes somos?, Barcelona: Paidós, 2004.

Keane, J., Reflexiones sobre la violencia, Madrid: Alianza Ensayo, 2000.

Kristeva, J., El genio femenino; 1. Hannah Arendt, Barcelona: Paidós, 2000.

Lagos, R., Landerretche, O., El Chile que se viene, Santiago de Chile: Catalonia, 2011.

Larrañaga, O., Azócar, I., "El nuevo escenario. Cambio demográfico, incorporación de la mujer y diversificación de la familia", en Tironi, E. (ed.), Redes, Estado y Mercados. Soportes de la cohesión social latinoamericana, Santiago de Chile: Uqbar Editores, 2008.

Lasch, C., La cultura del narcisismo, Barcelona: Editorial Andrés Bello Española, 1990.

— Refugio en un mundo despiadado, Barcelona: Gedisa, 1996.

Lévinas, E., Ética e infinito, Madrid: La Balsa de la Medusa, 1991.

Marcel, M., Rivera, E., "Regímenes de bienestar en América Latina", en Tironi, E. (ed.), Redes, Estado y Mercados. Soportes de la cohesión social latinoamericana, Santiago de Chile: Uqbar Editores, 2008.

— "Economía política de las finanzas públicas y políticas sociales en América Latina", En: Cardoso, F. H., Foxley, A., A medio camino. Nuevos desafíos de la democracia y del desarrollo en América Latina, Santiago de Chile: Uqbar Editores, 2009.

Norris, P., Derecha radical. Votantes y partidos políticos en el mercado electoral, Madrid: Akal, 2009.

Ortega Y Gasset, José (1959) En torno a Galileo Madrid: Revista de Occidente

Ridley, M., El optimista racional. ¿Tiene limites la capacidad de progreso de la especie humana?, Madrid: Santillana, 2011.

San Agustín, La ciudad de Dios, en Obras Completas, Madrid: BAC, 2000.

Payne, A., Phillips, N., Desarrollo, Madrid: Alianza Editorial, 2012.

Rousseau, J.J., El contrato social, 6ta edición, México: Porrúa, 1979.

Ruiz, R., "Chile y el estancamiento poblacional: Un análisis desde la perspectiva de la política exterior", en Revista Diplomacia, N²123, ISNN. 0716193X, Santiago de Chile: Academia Diplomática Andrés Bello, diciembre del 2010, Edición Bicentenario.

Sachs, J., Economía para un planeta abarrotado, Buenos Aires: Barcelona, 2008. 
Salazar, G., Poder popular Constituyente (Chile Siglo XXI), Santiago de Chile: LOM Ediciones, 2011.

Sartori, G., La sociedad multiétnica. Pluralismo, multiculturalismo y extranjeros, Madrid: Taurus, 2001.

— La tierra explota. Superpoblación y desarrollo, Buenos Aires: Taurus, 2003.

Thurow, L. C., El futuro del capitalismo, Buenos Aires: Javier Vergara Editor, 1996.

Todd, E., La ilusión económica, Madrid: Santillana, 2001.

- Después del Imperio. Ensayo sobre la descomposición del sistema norteamericano, Madrid: Akal, 2012.

Universidad Católica-Adimark, Encuesta Nacional Bicentenario, 2009 y 2011.

Valenzuela, S., Tironi, E. y Scully, T. (eds.), El eslabón perdido. Familia, modernización y bienestar en Chile, Santiago de Chile: Taurus, 2006.

Vásquez, M., "El capitalismo alemán sigue siendo mejor", en Revista de Asuntos Públicos, No759, Santiago de Chile: CED, 2009. 